\title{
About the shortwave multiple reflections in an urban street canyon building related to three different European climates
}

\author{
Chiara Colucci ${ }^{1, *}$, Luca Mauri $^{2}$, and Andrea Vallati $^{1}$ \\ ${ }^{1}$ Department of DIAEE, Sapienza University of Rome, Via Eudossiana 18, 00184 Rome, Italy \\ ${ }^{2}$ Department of Mechanical Engineering, University of Roma TRE, Via della Vasca Navale 79, 00146 Rome, Italy
}

\begin{abstract}
Energy exchanges between buildings is affected by urban fabric. As a matter of fact, heat exchange between adjacent buildings is due to convective and radiative heat flows. The main parameters which influence these heat exchange mechanisms are due to climate conditions such as air temperatures/humidity, wind speed/direction and solar irradiance. Most building energy simulations are done on an independent single building with typical meteorological year (TMY). These TMY meteorological data cannot represent the state of the urban microclimate and rather ignores the microclimate influence on buildings adjacent to street canyons. However, solar radiation shading and reflection of the environment within the street canyons are important factors affecting the energy consumption of buildings. In this work, a building energy simulation tool is used to study the impact of multiple shortwave inter-reflections in an urban environment. A street canyon model validated in a previous work was modeled in TRNSYS in order to simulate the effects of the urban radiative trapping. An urban canyon with aspect ratio $\mathrm{H} / \mathrm{W}=1$ was chosen, with South-North orientation, with transparent/opaque surfaces ratio Atr/Aop= 0.5 and 4 values $(0.2,0.4,0.6,0.8)$ of reflectance factor of the envelope surfaces. The goal is to characterize how solar absorption influence the urban energy requirements. The analysis was conducted for 3 cities in different climatic zones: Rome, Palermo and Krakow.
\end{abstract}

\section{Introduction}

Energy saving is an important priority in developed countries where a substantial part of energy consumption is represented by buildings. In recent years, many efforts have been made worldwide to improve buildings' energy efficiency and many political decisions have been discussed on this subject [1]. In the EU region, buildings account for about $40 \%$ of total energy consumption. For this reason, the "Building Energy Efficiency Directive" has been introduced [2] to prescribe requirements for either new and existing buildings. Building energy efficiency can be improved by implementing both active or passive energy efficient strategies. Improvements to heating, ventilation and air conditioning (HVAC) systems, electrical lighting, etc. can be classified as active strategies, whereas, improvements to building envelope elements can be classified under passive strategies [3-7]. The climatic characterization of an urban environment can present considerable difficulties depending on the topographic configuration of the urban environment, including narrow streets surrounded by buildings, squares, green areas and highly congested areas. Cities are also heat and pollution anthropogenic sources, as demonstrated by several studies that have attributed to urbanization radical changes in the radiative, thermodynamic and aerodynamic characteristics of the surface compared to those of the surrounding rural areas $[8,9]$. More in detail, meteorological parameters are modified such as: surface temperature, humidity, precipitation, fog, air quality, height of the mixing layer, wind profile. Many studies have also shown that building walls and road surfaces, acting as reflecting elements for solar radiation, cause radiative component bouncing and the accentuation of the overall effects on walls, ground and interposed air volume. Poor ventilation conditions caused by obstacles (e.g. buildings) help to generate and keep such stable and overheated air mass (named "thermal trap"). This mechanism boosts urban texture heat storage capacity in comparison to non-urban surroundings to an extend that depends on the different use of soil and buildings' geometry and materials. The whole phenomenon definitely builds the basis for a pollution increase and summer discomfort. To fully address this topic, it must be considered that a building is a system whose borders exchanges thermal energy with the surrounding environment. It means that urban areas conformation influences local microclimate, introducing differences in the boundary conditions compared to those occurring outside of the city, in rural areas. In this regard it is known, as confirmed by several studies, that the urban heat island (UHI) phenomenon plays an important role for what concerns the air temperature increase in the urban environment [10] and thus an alteration in buildings energy use [11, 12]. In other words, in urban canyons solar radiation affects buildings facades and tarmac and it is trapped in the form of multiple reflections. Of course, the same phenomenon (known as "canyon effect") does not

\footnotetext{
Corresponding author: chiara.colucci@uniroma1.it
} 


\begin{tabular}{|ll|}
\hline \multicolumn{2}{|l|}{ Nomenclature } \\
$\alpha$ & Absorptivity coefficient \\
$\varepsilon$ & Thermal emissivity \\
$\rho$ & Reflectance coefficient \\
$\mathrm{g}$ & Window's solar factor \\
$\mathrm{A}_{\text {tr }}$ & Trasparent surfaces \\
$\mathrm{A}_{\mathrm{op}}$ & Opaque surfaces \\
$\mathrm{H}$ & Henght of building \\
$\mathrm{W}$ & Width of building \\
\hline
\end{tabular}

occur in non-urban areas. Therefore, in cities, at night, air cooling inside the canyons is much slower than in outer space: infrared energy radiated towards the environment by canyons surfaces are mostly captured and reflected once again by the surrounding buildings rather than thin out in the free space. Various studies have been carried out on the intensity of the heat island for many cities. A study on energy consumption trends in Taiwan showed that energy consumption in urban areas is $81 \%$ higher than in rural areas [13].

In short words, the mutual interaction between buildings and urban environment generate the aggravation of operative conditions. For this reason, a holistic approach in the definitions of design choices for new and existing buildings is required to reach a smart planning for modern cities $[14,15]$. Building energy simulation codes (BES) are often used to estimate and predict the energy consumption of a building and the outdoor thermal conditions. Most energy simulations are performed considering a single isolated building [16] using a typical meteorological year (TMY) which do not account of the urban microclimate, since they were obtained from weather stations located in most cases in rural or suburban areas. Therefore, it is necessary to impose conditions that modify the TMY with the real conditions of the microclimate [17]. Recently, some researchers have begun using BES to study the space cooling demands of buildings, modeling their urban context more accurately, especially for what concerns radiations exchange [18].

The objective of this study is to evaluate how shortwave multiple reflections affect thermal energy demand (cooling and heating) of a street canyon building located in three different climatic zones: Rome, Palermo and Krakow. For this purpose, TRNSYS [19] has been exploited since its radiation data module considers interreflections between buildings, based on Gebhart factors formulation [20, 21], when a "false" zone method is adopted. More specifically, by modelling the street canyon as an interior thermal zone, TRNSYS applies the detailed radiation module calculating the multiple reflections both in the shortwave and in the longwave field. An urban canyon with aspect ratios $\mathrm{H} / \mathrm{W}=1$, orientations N-S, trasparent/opaque surfaces ratios $\mathrm{A}_{\mathrm{tr}} / \mathrm{A}_{\mathrm{op}}=0.5$ and 0.6 of solar absorption factor of the envelope surfaces. The total absorbed solar radiation on the external walls of the street canyon building were evaluated, such as the seasonal absorbed radiation. Finally, the influence on building thermal energy demands of multiple shortwave inter-reflections was evaluated comparing the results with a reference case with no interreflections. The results of study may contribute to rectify, by corrective factors, the data of predicted consumptions obtained by simulation tools that doesn't account of multiple reflections but only of shadowing factors. Considering that increases in cooling demand up to 54\% were found in Krakow, our numerical model underlines the importance of considering the multiple reflections inside urban environment for an accurate evaluation of thermal energy demands of buildings inserted in their actual context. The details about the conditions imposed for the numerical model in this work to account only of the shortwave multiple reflections are reported in Section 2.

\section{Methodology}

In this document, the dependence of the shortwave multiple reflections on the heating and cooling demand of a threefloor building for residential use was analyzed for three cities in different climatic zones: Rome, Palermo and Krakow. Simulations were performed for a building considered in an urban context, adjacent on both main long sides to street canyons. The BES software used to perform the numerical simulations in this work is TRNSYS 17.0, a transient 3D multi-zone building code able to simulate dynamically the energy behavior of a building with time steps of less than one hour.

\subsection{Numerical model}

In TRNSYS, conduction heat flow through enclosure components is modeled using the 1D transfer functions. About convection, constant values of the CHTC convection factor were chosen according to the standards (CHTC equal to $17.8 \mathrm{~W} / \mathrm{m}^{2} \mathrm{~K}$, while it is equal to $3 \mathrm{~W} / \mathrm{m}^{2} \mathrm{~K}$ for indoor surfaces). For solar irradiation, however, there is a model of radiation that considers multiple reflections only for internal thermal zones. This fact implies that, in case of a street canyon building modeled as an outdoor environment, the radiative model does not consider either the shortwave or the longwave inter-reflections between the façades of street canyon buildings. Since the final aim of this work is to investigate the influence of radiative trapping effect of the street canyon environment on the energy demand of a building, the space between the buildings was modeled as an interior thermal "false" zone with virtual border roof and walls.

As for the characteristics of the building studied, the length is $110.5 \mathrm{~m}$, since one of the purposes was to represent a long building with similar adjacent apartments but also to minimize the effects of the boundary conditions on the short sides of the building. Both the height $(\mathrm{H})$ and the width (W) of the building are $13.5 \mathrm{~m}$. The short side walls are modeled adiabatic assuming they are continuous, thus modeling a long row of identical thermal zones. The transparent surface on the long façades of buildings is $50 \%$ of the total surface. The $\mathrm{H} / \mathrm{W}$ (aspect ratio) is 1 and the orientation of the buildings is $\mathrm{S}-\mathrm{N}$, so the long façades facing the canyon are 
oriented E-W. The short side walls are modeled adiabatically assuming they are continuous, thus modeling a long row of identical thermal zones.

The street canyon building under analysis is surrounded by two other rows of buildings, geometrically identical to the studied building (Fig. 1). More details of the numerical model are reported in a previous work where a validation process has been performed [22]. Building's thermal energy demand for both heating and cooling is a function of the temperatures of its facades. These temperatures are influenced by both shortwave and longwave radiative exchange (in addition to convection and conduction). a)

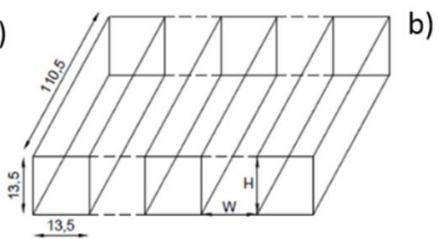

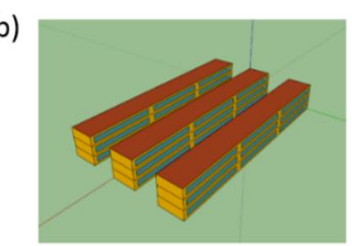

Fig. 1. a) Geometrical features and b) 3D overview of the street canyon.

However, the objective of this work is to evaluate the influence of the shortwave reflections on the thermal energy demand of the building only. For this reason, the longwave radiative exchange was deactivated by imposing the emissivity equal to 0 . By setting the model in this way, the longwave radiation losses to sky and to other surfaces has been disabled and the "false" zone method gives only the possibility to investigate the influence of shortwave interreflection as a comparison with a model without interreflection. The inter-reflection free model is such as the building envelope elements under study don't receive any reflections by surrounding surfaces. It means all the street canyon surfaces around the building under study have absorbance factor equal to 1: this model is named City_OFF. The model named City_ON is the model in which the shortwave multiple reflections are present. In this case, the value of the reflectance factor of the street canyon pavement is constant $(\rho=0.2)$. The simulations were carried out with the variation of the reflectance factors of the street canyon buildings façades change from $\rho=0.2$ up to $\rho=0.8$ as shown in Figure 2.

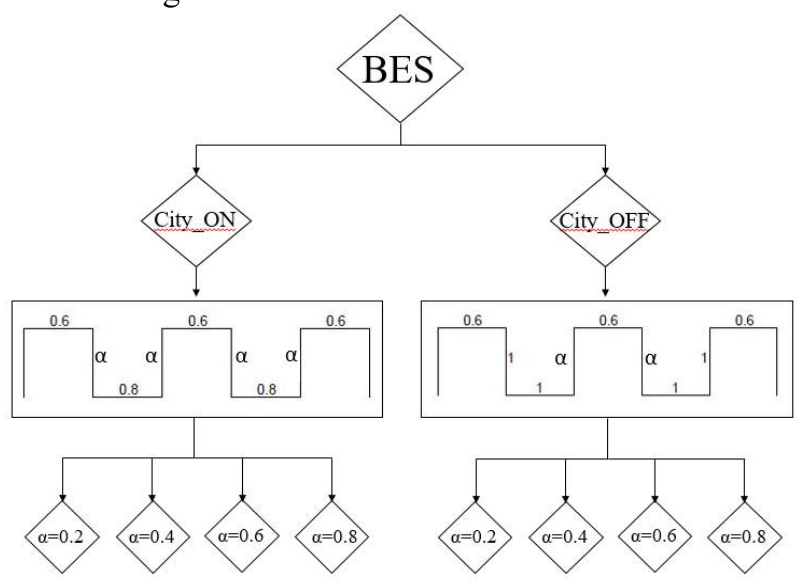

Fig. 2. Simulations scheme.

\subsection{Building energy simulation model}

The 3-floor central building is being analysed. The characteristics of the opaque and transparent elements of the envelope of all buildings are shown in Table 1.

In Tab. 1, g indicates windows solar factor. Internal gains due to the lighting system, electrical devices, users and occupancy schedules are set according to residential use as indicated in [23]. The gains reported in Table 2 are related to the total floor area. The presence of the users is considered for 24 hours per day. The usage schedule for the electrical devices is set "on" from 8.00 to 24.00 while for lights is set "on" from 17.00 to 24.00 .

Table 1. Main features of construction envelope.

\begin{tabular}{|c|c|c|c|c|}
\hline $\begin{array}{c}\text { Envelope } \\
\text { element }\end{array}$ & Materials & Thickness $(\mathrm{m})$ & $\mathrm{U}\left(\mathrm{W} / \mathrm{m}^{2} \mathrm{~K}\right)$ & $\mathrm{g}$ \\
\hline Walls & $\begin{array}{c}\text { Plaster, brick, } \\
\text { insulation }\end{array}$ & 0.44 & 0.36 & 0.32 \\
\hline Roof & $\begin{array}{c}\text { Plaster, concrete, } \\
\text { screed, insulation }\end{array}$ & 0.37 & 0.34 & 0.6 \\
\hline Pavement & $\begin{array}{c}\text { Ceramics, concrete, } \\
\text { isolation, plaster }\end{array}$ & 0.54 & 1.40 & 0.6 \\
\hline Windows & Glass, wood & - & & \\
\hline
\end{tabular}

Table 2. Specific values of internal gains.

\begin{tabular}{|c|c|c|c|}
\hline & $\begin{array}{c}\text { Persons } \\
\left(\mathrm{W} / \mathrm{m}^{2}\right)\end{array}$ & $\begin{array}{c}\text { Devices } \\
\left(\mathrm{W} / \mathrm{m}^{2}\right)\end{array}$ & $\begin{array}{c}\text { Lights } \\
\left(\mathrm{W} / \mathrm{m}^{2}\right)\end{array}$ \\
\hline Radiative & 1.51 & 0.35 & 3.5 \\
\hline Convective & 3.01 & 1.05 & 1.5 \\
\hline
\end{tabular}

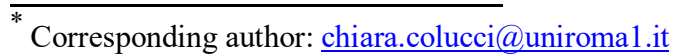


The daily natural ventilation rate is $0.3 \mathrm{vol} / \mathrm{h}$ while the envelope infiltration rate is assumed to be $0.2 \mathrm{vol} / \mathrm{h}$ while during night-time only the infiltration rate is imposed.

The weather files distributed with TRNSYS 17 are organized in directories according to the datasources. Currently there are two data sources:

- The US-TMY2 data sets from NREL (redistributed with NREL's permission). The dataset includes 237

Locations in the US (contiguous states + Alaska and Hawaii), and 2 files for Puerto-Rico and Guam.

- Selected worldwide stations from Meteonorm (distributed under license from Meteotest).

Weather data for the city of Rome, Palermo and Krakow are used as input for the BES. The heating period is imposed to be from 1st November to 15th April and the cooling period is not imposed by laws. Thus, the space cooling and space heating demands are determined considering the room air temperatures controlled to be at $20^{\circ} \mathrm{C}$ during the winter and $26^{\circ} \mathrm{C}$ during summer (considering as cooling period the days in which the internal temperature exceeds $26^{\circ} \mathrm{C}$ ).

\section{Numerical results}

The results show: i) the total amount of the solar energy absorbed with respect to the City_ON and the City_OFF cases in both summer and winter. Therefore, the percentage variation between the two conditions was obtained; ii) the standardized and absolute cooling and heating demands of the building in the City_ON and the City_OFF models. Measurements were performed in the cities of Rome, Palermo and Krakow. It is important to underline that the absorbed radiation values obtained are specific hourly average values and they refer only to the shortwave radiation field.

\subsection{Analysis of absorbed solar radiation}

In Table 3, on the left side, total absorbed solar radiation for each season is shown. These values are used to determine the percentage variations between the City_ON and City_OFF cases, reported on the right part of the same table. Such difference, is defined as follows:

$$
\Delta \text { Sol. } \text { Rad }_{\%}=\left(\frac{\text { City }_{\mathrm{ON}}-\text { City }_{\mathrm{OFF}}}{\text { City }_{\mathrm{OFF}}}\right) \times 100
$$

In general, observing Tab. 3 it can be stated that:

1. As the solar absorption factor $\alpha$ increases, no matter what the season is, the radiation absorbed by the walls of the building increases, both for the City_ON and the City_OFF cases. Accordingly, with the increase of $\alpha$, and the consequent reduction of the reflectance coefficient $\rho=1-\alpha$, the reflected solar radiation is smaller, hence the contribution of the inter-reflections is also reduced;

2. The East and West facades of the street canyon building undergo the same increase in radiation absorption, due to their symmetrical exposure to the daily solar path;

3. With the same $\rho$ value, the total solar radiation absorbed by the facades is greater in Palermo than in Rome and Krakow, especially in the summer.

Consequently, the percentage of the inter-reflections is also higher in Palermo.

Table 3. Values of absorbed solar energy $\left(\right.$ in $\left.\mathrm{MJ} / \mathrm{m}^{2}\right)$ in Inter_ON and Inter_OFF and Percentage variation of absorbed solar energy between Inter_ON and Inter_OFF cases for heating and cooling season.

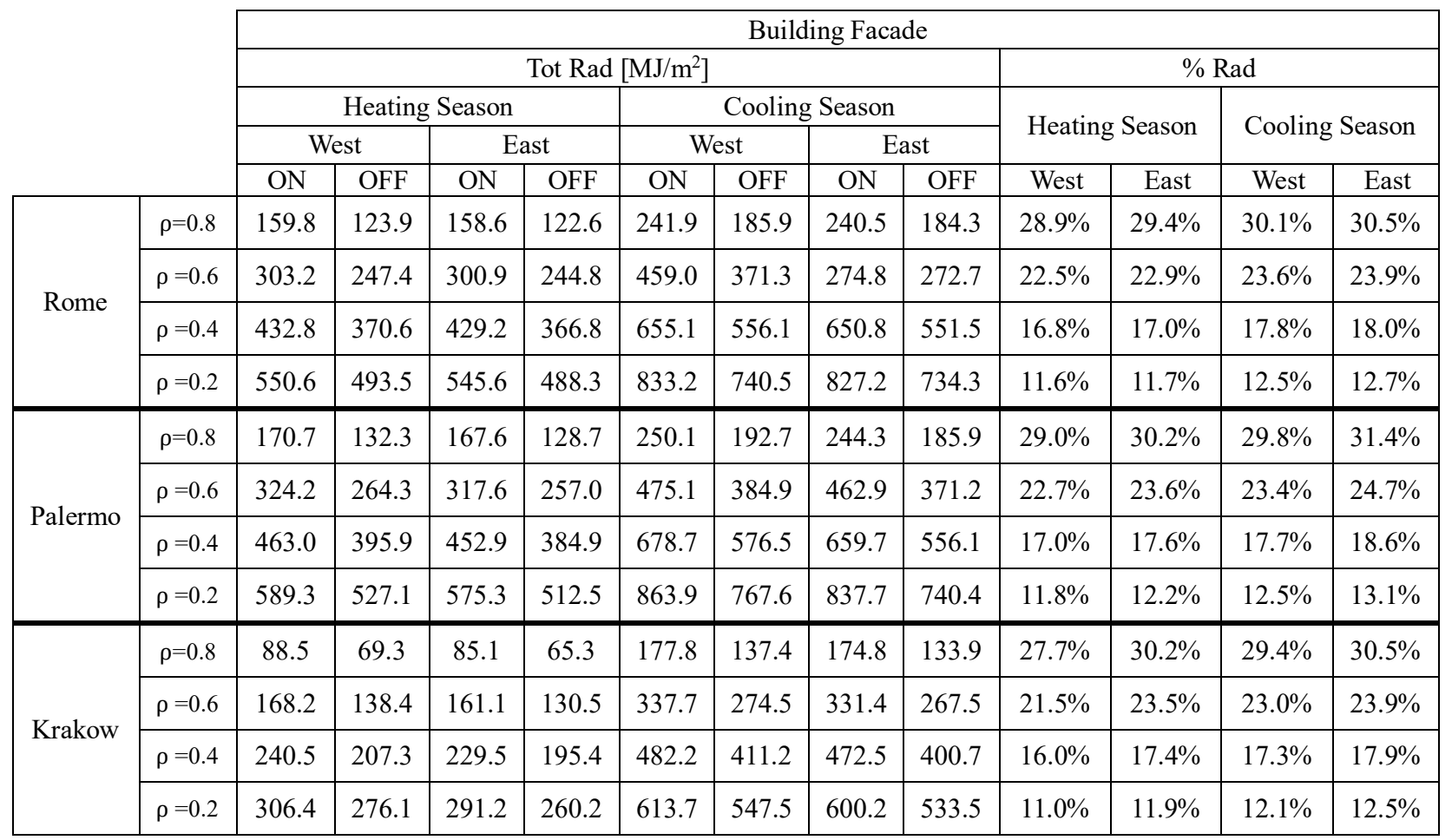

\footnotetext{
* Corresponding author: chiara.colucci@uniroma1.it
} 

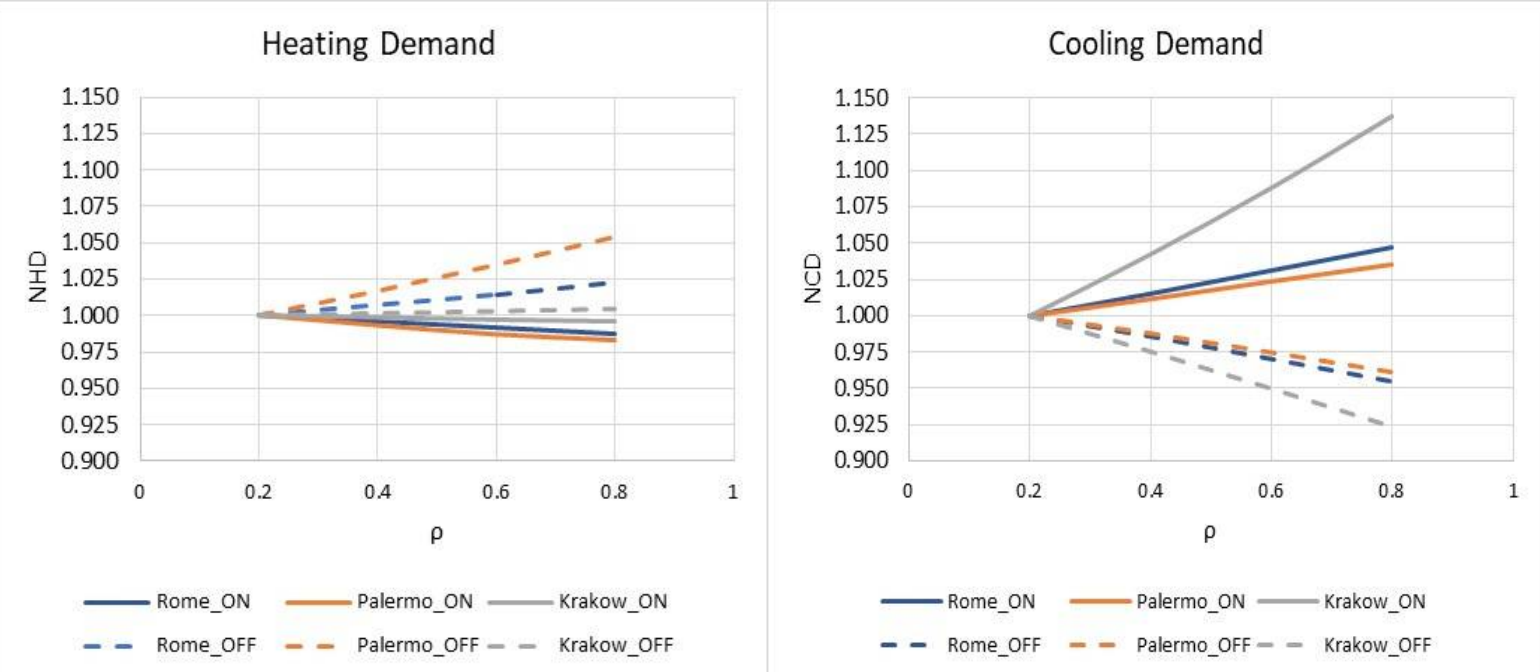

Fig. 3. Normalized Heating Demand (a) and Normalized Cooling Demand (b).
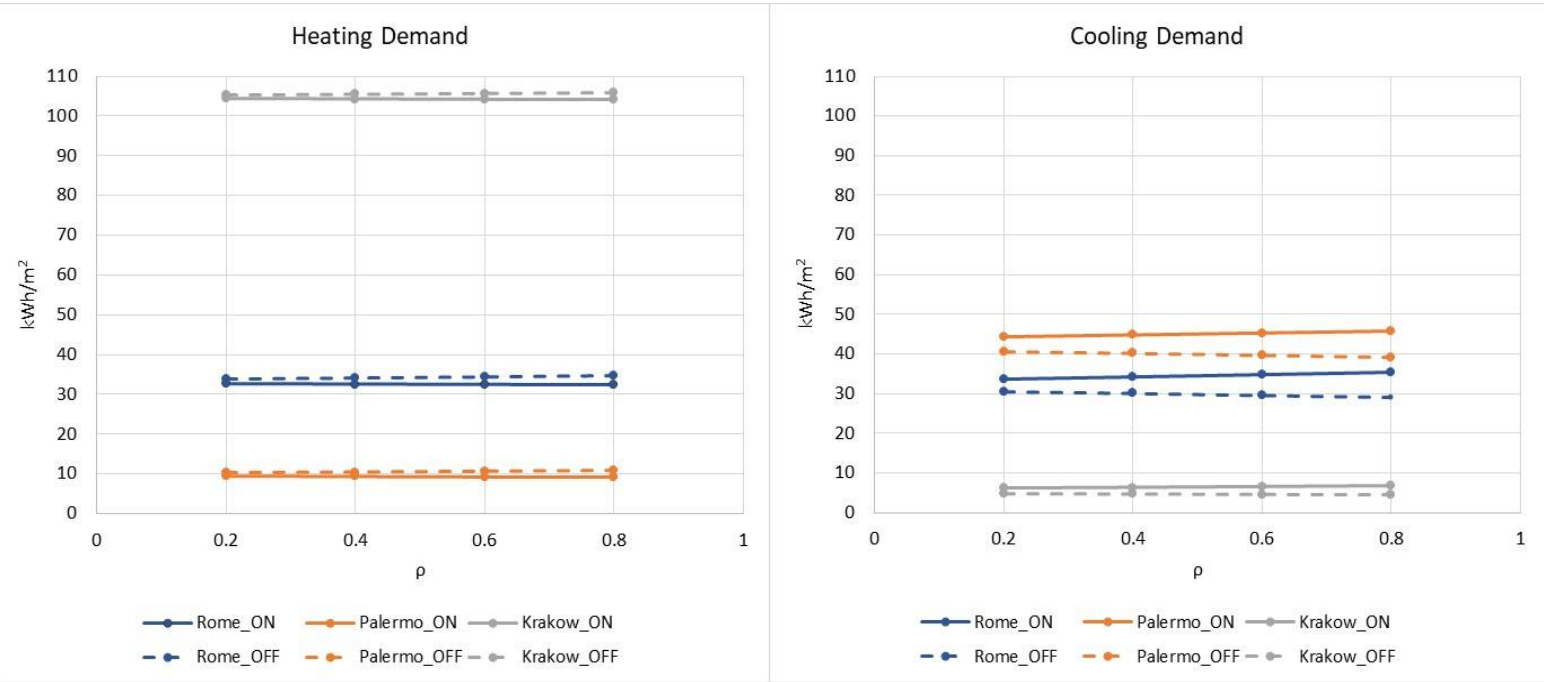

Fig. 4. Heating Demand (a) and Cooling Demand (b).

\subsection{Building thermal energy demand}

The work final purpose is to evaluate the impact of multiple canyon inter-reflections on the energy demands of buildings in Rome, Palermo and Krakow. The following figures show the thermal energy demand in both the City_ON and City_OFF cases while the solar reflectance coefficient $\rho$ and the city vary. The results show how the contribution of multiple inter-reflections affects heating and cooling demands when coefficient $\rho$ changes. For a better understanding of the energy demand variation as $\rho$ changes, in Fig. 3 results normalized with respect to the $\rho=0.2$ case are shown for both City_ON and City_OFF models.

Fig. 3 (a) shows, for the winter case, an increase in the heating demand accordingly to the reflectance coefficient $\rho$ growth for the City_OFF model (the less solar radiation absorbed by the building, the greater the heating demand). An opposite trend is shown for the City_ON case. This inversion of tendency is caused by inter-reflections. As seen in Table 3, as $\rho$ increases, inter-reflections become greater and this leads to a decrease for heating demand. In general, the normalized heating demand range between 1.05 and 0.98 .

The opposite situation can be seen in Figure 3 (b), which shows cooling demand for the summer period. In this case, as $\rho$ increases, cooling becomes more demanding for the City_ON case and less demanding in the City_OFF case (see Tab. 3). In general, normalized cooling demand ranges between 1.14 and 0.92 . Figure 4 makes clear how interreflections affect building energy demand by a different amount for each city. In Fig. 4 (a), as $\rho$ varies, interreflections impact on heating demand ranges from $-7.1 \%$ $(\rho=0.8)$ up to $-3.8 \%(\rho=0.2)$ for the city of Rome, from $14.3 \%(\rho=0.8)$ up to $-8.1 \%(\rho=0.2)$ for the city of Palermo, from $-1.8 \%(\rho=0.8)$ up to $-1 \%(\rho=0.2)$ for the city of Krakow.

Cooling demand for the summer season is shown in Fig. 4 (b): in Rome it increases from $10.5 \%(\rho=0.2)$ up to $21.1 \%$ $(\rho=0.8)$, from $8.7 \%(\rho=0.2)$ up to $17.1 \%(\rho=0.8)$ for Palermo and from $25.1 \%(\rho=0.2)$ up to $54 \%(\rho=0.8)$ in the city of Krakow. The last percentage value is due to the fact 
that Krakow's standard cooling load is approximately just 6 $\mathrm{kWh} / \mathrm{m}^{2}$.

Considering both the two figures, for the same city and $\rho$ value, percentage difference in demand between City_ON and City_OFF models is lower in the winter than in the summer $(7,1 \%$ compared to $21,1 \%)$. The reason for this is that in the winter temperature difference between the inside and the outside of the building is greater than in the summer. Therefore, when defining building's thermal load, it has a major influence than inter-reflections.

\section{Conclusions}

For this work, a virtual residential building flanked by two other identical building has been simulated in TRNSYS using the "false zone" method developed and validated in a previous work. In this way, the model allows to account of the multiple radiative reflections between facing surfaces by calculating the values of the Gebhart factors. Measurements were carried out considering three different cities, each of them representative of different climatic zones: Krakow, Rome and Palermo.

Since the final scope was a comparison with respect to a model without inter-reflections, two similar models were set up. In the model without inter-reflection, named City_OFF, the building envelope elements under study doesn't receive any reflections by surrounding surfaces for a specific setting of albedo values. The model named City_ON is the one in which the shortwave multiple reflections are present. The transparent surface on the long façades of buildings is $50 \%$ of the total surface. The H/W (aspect ratio) is 1 and the orientation of the buildings is South-North, so the long façades facing the canyon are oriented East-West.

By comparing the results of the two models (City_ON and City_OFF), an increase in the heating demand for the winter case is shown, accordingly to the reflectance coefficient $\rho$ growth for the City_OFF model. An opposite trend is shown for the City_ON case. In the summer, instead, as $\rho$ increases, cooling demand increases for the City_ON case, whilst it decreases in the City_OFF case. This due to inter-reflections. At a deeper lever, having fixed $\rho=0.8$ in order to analyze the phenomenon at his greatest effect, simulations show an increase in cooling demand up to $54 \%$ and a decrease in heating demand up to $1.8 \%$ in the city of Krakow. The same variations are $+21.1 \%$ and $-7.1 \%$ for the city of Rome and $+17.1 \%$ and $-14.3 \%$ for the city of Palermo. For what has just been said, the analysis shows the extend of the error in thermal energy demand evaluation that occurs if the inter-reflection effect isn't taken on account. In general, during the summer the radiative trap phenomenon is greater than in the winter. This led to a bigger growth of cooling demand rather than heating demand. The reason for this is that in the winter temperature difference between the inside and the outside of the building is greater than in the summer. Therefore, when defining building's thermal load, it has a major influence than inter-reflections.

Given the results shown, this work suggests to consider as driving parameters to define thermal energy demand of new buildings also their interactions with the surrounding environment. This in order to take on account every possible solution to optimize the energy performance of the building itself.

\section{References}

1. R. Pacheco, J. Ordóñez, G. Martínez, Renew. Sustain. Energy Rev., 16 (2012)

2. EPBD 2012 - Directive 2012/27 / EU of the European Parliament and of the Council of 25 October 2012 on energy efficiency

3. R. De Lieto Vollaro, F. Faga, A. Tallini, L. Cedola, A. Vallati, Energy Procedia, 82 (2015)

4. A. Tallini, A. Vallati, L. Cedola, Energy Procedia, 82 (2015)

5. A. Vallati, S. Grignaffini, M. Romagna, L. Mauri, EEEIC 2016 - International Conference on Environment and Electrical Engineering 7555731 (2016)

6. A. Vallati, S. Grignaffini, M. Romagna, Sustainability (Switzerland), 7 (2015)

7. P. Ocłoń, M. Bittelli, P. Cisek, E. Kroener, M. Pilarczyk, D. Taler, R.V. Rao, A. Vallati, Applied Thermal Engineering, 108 (2016)

8. M. Ignatius, N.H. Wong, S. K. Jusuf, Sustainable Cities and Society, 19 (2015)

9. E. Erell, D. Pearlmutter, D. Boneh, P.B. Kutiel, Urban Climate, 10 (2014)

10. G. Evola, A. Gagliano, A. Fichera, L. Marletta, F. Martinico, F. Nocera, A. Pagano, Energy Procedia, 134 (2017)

11. M. Palme, L. Inostroza, G. Villacreses, A. LobatoCordero, C. Carrasco, Energy and Buildings, 145 (2017)

12. A.D.L. Vollaro, G. Galli, A. Vallati, R. Romagnoli, Journal of Physics: Conference Series 655(1),012056 (2015)

13. R.-L. Hwang, C.-Y. Lin, K.-T. Huang, Energy and Buildings, 152 (2017)

14. G. Battista, E. Carnielo, L. Evangelisti, M. Frascarolo, R. De Lieto Vollaro, Sustainability, 7 (2015)

15. G. Battisti, E. Carnielo, R. De Lieto Vollaro, Energy and Buildings, 133 (2016)

16. F. Calcerano, L. Martinelli, Energy and Buildings, 112 (2016)

17. J. Allegrini, V. Dorer, J. Carmeliet, Energy and Buildings, 55 (2012)

18. J. Allegrini, V. Dorer, J. Carmeliet, Energy and Buildings, 127 (2016)

19. S.-A. Klein, TRNSYS 17: A Transient System Simulation Program. Solar Energy Laboratory, University of Wisconsin, Madison, USA (2010)

20. B. Gebhart, International Journal of Heat and Mass Transfer, 3 (1961)

21. B. Gebhart, Heat Transfer. 2nd. New York: McGrawHill (1971) 
22. A. Vallati, L. Mauri, C. Colucci, P. Ocłoń, Energy and Buildings, 149 (2017)

23. 11300-1, UNI TS. Energy Performance of Buildings-Part 1. Calculation of Energy Use for Space Heating and Cooling. 1st ed. Milano: UNI, (2014) 